\title{
Um sinólogo frente à China. Reflexões atuais e inatuais ${ }^{1}$
}

Jean François Billeter ${ }^{2}$

Talvez pensem que um sinólogo sabe tudo da China; que poderia falar a respeito com facilidade; e que, se ele se expressa pouco, é que é preguiçoso ou tímido, ou então paralisado por escrúpulos inúteis. No meu caso, a razão é diferente, pois me interesso por questões que são afastadas daquelas que agitam a opinião pública. Não me desinteresso do presente, muito pelo contrário, mas o faço de forma inatual, por assim dizer.

Desde que me voltei para os estudos chineses, há uns cinquenta anos, constato que se desenvolveram de forma extraordinária, mas com um efeito muito reduzido, até mesmo nulo, em algumas áreas, sobre as ideias do público, mesmo culto, a respeito da China, de sua história e de sua civilização. Esta não-comunicação tem várias causas.

A primeira é que o passado chinês está como obliterado. É o caso quando penso em Pequim na época em que cheguei lá pela primeira vez, em 1963. O transiberiano seguia longamente as muralhas da cidade, do lado oeste e, em seguida, sul, antes de chegar a uma nova estação onde não havia quase ninguém. As grandes avenidas se concluíam ao norte, sul, leste e oeste por antigos portões. Isso dava a medida do que havia sido a capital do império durante oito séculos. O habitat tradicional, essencialmente herança da época mongol, estava praticamente intacto. Grupos de crianças brincavam nas ruazinhas onde não circulavam quaisquer veículos. Quando passava por um destes portões, encontrava-me quase imediatamente no campo. Da escola de língua, onde passei os primeiros meses, podia se ver, no meio dos campos, uma aldeia composta de algumas casas de taipa e árvores que lembravam as pinturas da época Song. A Universidade de Pequim estava circundada por arrozais. Durante as noites de verão, os sapos causavam um barulho ensurdecedor. Nas lojas estatais, fazia-

\footnotetext{
${ }^{1}$ Conferência na Secção Romanda da Sociedade Suíça-China, Lausanne, março 2014. Tradução Christine Dabat. A tradutora agradece a Bruno Pontes Motta pela paciente e precisa correção do português.

${ }^{2}$ Professor emérito da Universidade de Genebra, Suiça. Contato: Universidade Federal de Pernambuco, CFCH, Dept. de História, 11. andar, Av. da Arquitetura, s/n, CEP: 50740-550, Cidade Universitária, Recife-PE, Brasil. E-mail: cadernosdehistoriaufpe@gmail.com.
} 
se as contas de ábaco na mão, com uma louca destreza. As lojinhas improvisadas instaladas para a venda das frutas da estação estavam ornamentadas por inscrições executadas com pincel por artesãos que eram artistas. No inverno, à noite, a estrada que seguia o limite da universidade era percorrida por intermináveis filas de carros carregados de repolhos, puxados, cada um, por um pequeno cavalo e um jumento. Fora o primeiro da fila, os condutores dormiam em cima dos repolhos. Assim, os camponeses abasteciam a cidade. Ainda vi, uma vez, fora dos muros, uma caravana de camelos trazendo carvão da Mongólia. Tudo isto pertence agora ao passado, em Pequim como na maior parte da China.

Mas hoje, o passado está obliterado de outro modo. A história só tem sentido se ela for interpretada e der lugar a uma narrativa. Vi essa mudar várias vezes, na própria China. O momento mais interessante foi o decênio de 1980, quando os intelectuais chineses puderam debater publicamente sobre questões fundamentais: particularmente a da continuidade entre a China de Antigo Regime e seu sistema mandarinal, de um lado, e o novo regime, do outro. Essa questão, entre outras associadas, suscitou um grande interesse numa parte da opinião pública chinesa da época. Após a repressão do levante democrático de 1989, quando o regime ficou abertamente reacionário, estas discussões foram brutalmente interrompidas e não retomaram desde então, pelo menos não na esfera pública. A atual propaganda sobre a grandeza passada da China e a excelência de sua cultura tradicional é intelectualmente oca. Contudo, não é ideologicamente neutra: ela constitui um interdito imposto ao pensamento crítico.

O milagre econômico que deixa o mundo estupefato, nos últimos vinte anos, contribuiu também de forma cabal a apagar o passado. Em primeiro lugar, porque criou uma realidade completamente nova, mas também porque impôs o discurso econômico como o único pertinente a respeito da China. Os homens de negócios deram o tom. $\mathrm{O}$ desenvolvimento rápido de uma sociedade de consumo, imitando a nossa, reduziu ainda a distância, pelo menos em aparência, entre os chineses e nós. E isto diminui proporcionalmente nossa curiosidade. Doravante, quando surgem dificuldades de compreensão entre nós e nossos interlocutores chineses, tende-se a explicá-las pelas "culturas" diferentes e esquecer que estas "culturas" só podem ser compreendidas pela história que as produziu. Sem a história, apelar para "culturas" fornece apenas explicações carentes. 
Obliterar a história, ou escamoteá-la, cria um tipo de carência que muitos sentem, mas não conseguem nomear. Não estou pensando, em primeiro lugar, em todos aqueles que lidam cotidianamente com a China: os homens de negócios que aí tem afazeres; os jornalistas que analisam sua evolução; os sinólogos que se dedicam a suas pesquisas; os especialistas de todo tipo que praticam intercâmbios com seus homólogos chineses. Penso mais no público que está mais afastado, como o sou atualmente, e que, frente à China, sente certo mal estar que não sabe como formular.

Quando ele se dirige aos sinólogos, é, muitas vezes, decepcionado: não encontra entre eles respostas a seu questionamento. Ele se pergunta até, às vezes, para que servem os sinólogos, ou se esta apelação corresponde ainda a alguma coisa, pois encontra, com frequência, apenas especialistas: conhecem a filosofia chinesa antiga, ou tal religião, ou tal período histórico, ou ainda, para hoje, economistas, sociólogos, cientistas políticos, juristas, linguistas etc. Perguntei-me já, certa vez, se o termo sinólogo não deveria ser abandonado em prol de denominações mais precisas correspondendo à atual divisão acadêmica do saber.

Pensando bem, considero que sinólogos ainda são necessários, mas convém dar a este termo um novo sentido. Definiria sinólogo como aquele capaz de ultrapassar a barreira do idioma e de ajudar outros a fazer o mesmo - ultrapassar a barreira da língua como se faz com a barreira de coral quando se deixa um atol.

Será que isso importa? dir-me-ão. Não tem cada vez mais ocidentais que aprendem chinês e o falam cada vez melhor? Não há novas gerações de chineses que falam muito bem nossas línguas, em primeiro lugar o inglês? Esta nova situação facilita, de fato, os contatos, mas apenas a um nível superficial. Por baixo, a barreira subsiste, quase que intocada. Mas, para se dar conta disto, tem que mergulhar. É preciso tocar nas palavras-chave que estão carregadas de história; que resumem certos aspectos de sensibilidade; que estruturam as relações sociais e a personalidade moral assim como todo o pensamento tradicional. Ora, estas palavras, seja num sentido, seja em outro, não se encontram na língua do outro. Enquanto falamos nosso próprio idioma com nossos amigos chineses, ou parceiros e colaboradores, ele forma como se fosse um espelho que nos manda de volta nossa própria imagem. É como se nos olhássemos na superfície da água, como Narciso, sem ver o que tem por baixo. Ora, sob a superfície, não há 
profundezas turvas, mas outro mundo, estruturado por outra linguagem, herdeiro de outra história.

Não pensem que, ao usar tais imagens, eu queira sugerir que este outro mundo seja inacessível ou misterioso. Não. Apenas procuro mostrar de que ordem são as verdadeiras dificuldades, na passagem de um mundo ao outro, de modo que se providenciem verdadeiras soluções e se torne possível uma exata compreensão novamente, nos dois sentidos. Vou mostrar com alguns exemplos até que ponto as palavras são carregadas de história.

Zhangbei 长辈 e wanbei 晚辈 são duas palavras banais em chinês. A primeira designa, numa família, a geração mais velha; a segunda, a mais nova. Muito recentemente, no primeiro dia do ano do cavalo, telefonei a uma sobrinha de minha esposa, que era chinesa. A sobrinha mora em Taiwan e foi o esposo desta que atendeu. "Estou chamando para lhe desejar um Feliz Ano Novo", disse, e ele me respondeu: "É o mundo de cabeça para baixo! Quem já viu zhangbei se antecipar para desejar Feliz Ano Novo a wanbei!" Ele falava rindo, mas não era anódino. Minha esposa, nascida em Pequim, tornou-se, com o tempo, advogada convencida dos valores democráticos suíços, mas, às vezes, o fundo chinês ressurgia. Por ocasião de um conflito com um sobrinho, e em virtude do fato de que este conflito lhe dava preocupações, eu lhe disse: "Vamos, tome a iniciativa", ao que me respondeu com muita determinação: "De jeito nenhum! Sou zhangbei, e é wanbei que tem que dar o primeiro passo.” Estávamos num verdadeiro conflito de valores. Para mim, a pessoa mais velha, reputada mais sábia, deveria tomar a iniciativa. Mas, não: a hierarquia das gerações teve primazia. Isto ofuscava minha concepção cristã do perdão, e não obtive ganho de causa.

O interessante é que o respeito absoluto à hierarquia familial vem de muito longe. ${ }^{3}$ Ele remonta a um evento histórico antigo, aquele da criação da organização da aristocracia chinesa, classe dirigente da dinastia dos Zhou, por volta do ano mil antes de nossa era. Esta organização era indistintamente familial, religiosa e política. Familial na sua terminologia, pois na grande família aristocrática todas as relações eram hierárquicas, dando sempre poder a alguém, ou pelo menos prioridade cerimonial sobre outro. Ela foi concebida de modo a poder se estender sem que jamais se introduzisse a

\footnotetext{
${ }^{3}$ São retomadas aqui noções de história expostas na segunda parte de Chine trois fois muette. (China três vezes muda. Paris: Allia, 2000; ed. revista e corrigida, 2010), intitulada "Breve ensaio sobre a história chinesa de acordo com Spinoza", p. 102 et s.
} 
menor desordem. Podia abranger várias dezenas, ou centenas, até mesmo milhares de membros, reunindo até quatro gerações simultaneamente, sem que houvesse nunca ambiguidade alguma quanto à ordem de prioridade entre dois membros, quaisquer que fossem. Nem que seja do ponto de vista formal, este sistema é, sem dúvida, uma das grandes criações do espírito humano.

Pode-se dizer que esta extraordinária criação tornou-se uma das matrizes da civilização chinesa. Encontra-se um rastro no fato de que, hoje ainda, existem não apenas uma, mas duas palavras para “irmão”: gege 哥哥 (ou xiong 兄), para o irmão mais velho, didi 弟弟 para o irmão mais novo. Quando se traduz em chinês o lema da República francesa, “fraternidade”, escreve-se xiongdi 兄弟, que significa literalmente “os irmãos mais velhos e os irmãos mais novos". Não é exagerado dizer que, na China, todas as relações humanas são oriundas dessa matriz hierárquica, a ponto que o fenômeno humano elementar não foi concebido como um átomo, mas como um binômio hierarquizado. $\mathrm{O}$ outro grande princípio foi aquele da linhagem, da qual não falarei aqui. Podem constatar que, da mesma forma que uma muito pequena quantidade de matéria basta para o químico analisar uma substância, algumas palavras bastam ao sinólogo para voltar muito tempo atrás na história.

Agora, outro caso de figura é aquele de uma palavra que usamos para falar da China e que nos induz ao erro: a palavra "confucianismo". Este termo leva a crer que se trata de uma doutrina que remonta a Confúcio, enquanto o termo chinês, rujia 儒家, não comporta referência alguma à pessoa. Ele designa uma tradição letrada, melhor dito, erudita, pois centrada no conhecimento de textos antigos, que forneceu ao império a ideologia da qual precisava para se justificar e durar. Esta ideologia imperial formou-se séculos após a morte de Confúcio (551-479 antes da era comum), mas ela se autoproclamou sua herdeira e fez dele seu santo patrono. A este título apenas, pode-se qualificá-la de "confucianista". Trata-se de uma ideologia profundamente conservadora, fundada no respeito às hierarquias e particularmente aos sacrossantos san gang 三纲, os "três princípios" que são a submissão do súdito ao príncipe, do filho ao pai e da esposa ao seu esposo. ${ }^{4}$ Em comparação, o Confúcio histórico parece ser um personagem muito

\footnotetext{
${ }^{4}$ A seguir, duas das fórmulas canônicas: Sangangzhe he wei ye ? Jun chen, fu zi, fu fu ye

三纲者何谓也? 君臣, 父子, 夫妇也. (Baihu tongyi 白虎通义) Jun wei cheng gang, fu wei zi gang, fu wei fu
} 
livre e pouco convencional, de certo modo, bastante amável que, depois de fracassar nas suas ambições reformadoras, tentou agir ao se tornar educador. Esta bela independência desapareceu da ideologia imperial que dele se diz herdeira. É contra esta ideologia conservadora que a juventude estudante chinesa se levantou por ocasião do grande Movimento de maio de 1919, o verdadeiro pontapé da revolução contemporânea. Que os institutos promovidos em todo lugar pelo atual governo chinês se chamem "Institutos Confúcio" é a marca evidente de que a China atual está numa fase de restauração ideológica.

Contudo, voltemos ao problema terminológico. Mencionar de maneira uniforme o "confucianismo" onde os próprios chineses utilizam outro termo - ou melhor, vários deles, que permitem estabelecer indispensáveis distinções - nos impede de apreender a história e as prolongações que ela opera no tempo presente. Os sinólogos sabem disso. Todavia, o público mais afastado da China o ignora, e permanece perplexo. Notações análogas poderiam ser feitas a respeito do taoismo, termo tão simplista e enganador que confunde o que é designado, em chinês, com razão, por cinco a seis palavras diferentes.

Parece-me, portanto, que o sinólogo pode ter um papel útil ao clarificar o sentido dos termos, palavras chinesas e palavras ocidentais. Acredito que ele possa também ajudar assim o público a compreender as causas de certa dificuldade não formulada que ele sente frente à China. Pois isto é devido, em boa parte, à obliteração da história mencionada acima.

A China carece de narrativa. Primeiro, no plano interior. $\mathrm{O}$ regime não pode adotar um discurso de verdade sobre o que aconteceu desde sua fundação, em 1949. Não tolera que seja feito no seu lugar, ou que haja um debate público sobre esta história. $\mathrm{Na}$ época em que eu estudava em Pequim, nos anos 1960, a saga revolucionária de antes de 1949 gozava ainda de todo seu prestígio. Ela está bastante desgastada agora. Parece mais uma velha relíquia que continua sendo exibida em alguns rituais congelados. Os grandes momentos do verdadeiro movimento operário chinês, nos anos 1920, e o extraordinário desabrochar do pensamento crítico e do questionamento do passado que caracterizou os anos 1920 e 1930 não são mais sequer evocados, obviamente. Permanece apenas uma única narrativa usada e abusada pelo regime, aquela dos 
horrores da invasão japonesa. Outra é aquela da grandeza passada da China, que é suposta voltar em breve. Contudo, parece mais um sonho do que uma narrativa, na medida em que, propositadamente, não são expostas as dinâmicas exatas desta grandiosidade passada. Outro sonho é a democracia, que o regime é obrigado a prometer, pois ele não sabe o que mais prometer no plano político. Por enquanto, esforça-se para que este sonho seja semelhante a um horizonte que recua na medida em que se avança em sua direção.

Poderiam objetar que numerosos intelectuais chineses têm consciência aguda deste impasse e o debatem muito entre si. Da mesma forma, poderiam também objetar que há uma luta constante entre o regime, que não quer a verdade sobre a história recente, e aqueles que a querem, ou seja, que as linhas de frente não param de se mexer. Mas sabem também que o regime define as linhas que não podem ser ultrapassadas, e sanciona quem o fizer. Há, ademais, a dificuldade intrínseca aos problemas postos que faz com que os intelectuais tenham, muitas vezes, dificuldades para se por de acordo entre si. Um ensaísta que aprecio muito, Li Ling, arqueólogo e historiador da China Antiga, professor na Universidade de Pequim, conta, num de seus livros recentes, como foi convidado, entre outros eminentes historiadores, a debater em petit comité da maneira como deveria ser apresentada a história chinesa no Museu Nacional de História da Praça Tiananmen, então em reforma. Não conseguiram se pôr de acordo sobre a periodização, nem a terminologia, de modo que os objetos expostos neste museu, desde sua reabertura, não dizem nada, por falta de narrativa. ${ }^{5}$

Após a votação de nove de fevereiro (2014), ${ }^{6}$ Le Temps publicou um excelente artigo de Andreas Saurer, um médico psicoterapeuta e psicanalista intitulado "Les Suisses de 1291 et ceux de 1848 face à face". ${ }^{7}$ Este texto foi uma resposta à fala de Blocher" quanto à "menor consciência nacional dos romandos". A ideia que um cidadão suíço faz de si mesmo e da sociedade na qual vive, dizia o autor do artigo, varia consideravelmente de acordo com o fato dele situar a origem desta sociedade em 1291 ou em 1848. No primeiro caso, a Suíça romanda está excluída, no segundo, ela tem um papel importante. Este tipo de debate é essencial para compreender quem somos e para que possamos determinar o que queremos. Os debates desta natureza são essenciais na

\footnotetext{
5 李零, 放虎归山 (山西人民出版社, 太原, 2008), p. 166-171.

${ }^{6}$ Nesta data, os eleitores aprovaram um sistema de cotas para imigrantes. N.d.t.

7 "Os suíços de 1291 e os de 1848 frente a frente". Número de 28 de fevereiro de 2014. Disponível em https://www.letemps.ch/opinions/suisses-1291-1848-face-face. Acessado em 28 de janeiro de 2018.

${ }^{8}$ Político de extrema direita, presidente da União Democrática do Centro. N.d.t.
} 
China, mas as implicações são de dimensões tão dramáticas que são proibidas pelo poder, ou então, quando toleradas, submetidas a uma supervisão severa. Esta situação cria uma frustração cujos efeitos se fazem sentir até aqui, geralmente sem entendermos de onde vêm.

A ausência de narrativas suficientemente convincentes da história chinesa me incitou a conceber uma. Precisava dela para o ensino, mas sobretudo para mim mesmo, por necessidade de entender. Em dado momento, uma narrativa tomou forma e a formulei num ensaio que constitui a segunda parte de um pequeno livro intitulado Chine trois fois muette. O fio condutor consiste em certa concepção do poder, acima mencionada, surgida por volta do ano 1000 antes da era comum, que evoluiu ao fio dos séculos, adaptando-se a profundas modificações econômicas e sociais, mas possuindo traços invariáveis que persistem até nossos dias. De tal modo que meu breve ensaio, que defendo ainda, quinze anos depois, constitui também uma contribuição à filosofia política. Pois a forma chinesa do poder pode ser acrescida à lista das formas clássicas que conhecemos: aquelas do despotismo, da monarquia e da república. É um despotismo, certamente, embora de uma natureza peculiar, que não nos é fácil compreender, pelo menos num primeiro momento, pois é embasado em ideias que não nos são familiares. Aqui está um trecho de Chine trois fois muette que poderá dar dele uma pequena ideia_:

Os fundadores de Zhou instauraram um regime dividido em duas esferas: uma superior, da aristocracia minuciosamente hierarquizada, estreitamente unida pela sofisticada repartição dos privilégios, os laços familiais, os ritos - e uma esfera inferior, aquela do conjunto das populações submetidas, muito diferentes entre si quanto às instituições sociais, costumes e práticas religiosas. Elas eram livres para viver como bem queriam porquanto que permanecessem submissas. Novamente, os Zhou não se contentaram com o estabelecimento de uma dominação de fato. Criaram uma ordem que se tornou um dos alicerces da civilização chinesa, uma ordem cuja pegada pode ser encontrada na representação do mundo e até nas categorias do entendimento chinês. Poder-se-ia dizer, em termos mais habituais, que a esfera superior, uma e dominante, representou, a partir de então, o universal, e a esfera inferior, dividida e diversa, o particular. As categorias chinesas que dão conta desta relação são o Céu e a Terra, ou o yang e o yin - em cima, o Céu, ou yang, que é unificado e domina aquele que é diverso ao organizá-lo; em baixo, a Terra, ou yin, que é desunida e tende à desordem e que precisa ser organizada. Para compreender as noções de yin e de yang, é preciso se dar conta que são, no fundo, categorias sócio-políticas.

\footnotetext{
${ }^{9}$ Chine trois fois muette. Op. cit., p. 110-114.
} 
Parece-me que não foi suficientemente mensurado até que ponto o mundo chinês foi marcado, nas suas instituições, nas suas representações e até nas categorias de seu entendimento, por esta divisão da realidade social em duas partes diferentes, ligadas entre si por interações de formas assimétricas e em movimento. Não me surpreenderia que se descobrisse, um dia, nesta divisão um princípio estruturante tão determinante quanto o princípio das três funções que Georges Dumézil pensou ter percebido no mundo indo-europeu. ${ }^{10}$

Ao reconhecer este princípio, não se negará de forma alguma o caráter plenamente histórico do passado chinês. Pelo contrário, compreenderse-á muito melhor esta história já que ela será apreendida, enfim, de acordo com suas próprias categorias. Ver-se-á então como, várias vezes, após grandes transformações tecnológicas, econômicas e sociais, uma ordem recriou-se: chinesa, porque baseada nesta divisão. A primeira grande ordem deste tipo foi a realeza aristocrática dos Zhou; a segunda, o império burocrático fundado por Qin Shihuang; a terceira, o império aristocrático dos Tang, em seguida, mandarinal dos Song, dos Ming e dos Qing. O regime atual se apoia nas mesmas bases. O Partido Comunista Chinês reestabeleceu, mais uma vez, a divisão tradicional da sociedade em duas esferas. Contudo, desta vez, o cruzamento da tradição chinesa com a tradição bolchevique e outros elementos de proveniência ocidental produziu uma mistura instável, cujo futuro é incerto.

Para dar um sentido à história chinesa, devemos, ao meu ver, não apenas reunir os fatos de modo que eles formem uma narrativa coerente, mas colocá-la frente àquela que fazemos de nossa própria história, situando ambas, portanto, num mesmo campo que só pode ser um esboço de uma história universal. Minha reflexão vai neste sentido. Pensei ter descoberto algo importante quando, há alguns anos, Mu Zhongjian, professor de história da filosofia chinesa na Universidade das Nacionalidades de Pequim, me ofereceu um pequeno livro que acabara de publicar com um dos seus colegas, nas edições da Escola Superior do Partido. ${ }^{11}$ Esta obra era uma proposta, até um programa. Apresentava 85 obras, desde as origens até o fim da última dinastia imperial, no começo do século $\mathrm{XX}$, que constituíam, de acordo com os autores, a fina flor do que a civilização chinesa havia produzido nos domínios da filosofia, letras, historiografia, ciências e que, idealmente, um dia, todo cidadão chinês culto deveria conhecer. Uma lista restrita a dez livros constituía o mínimo exigido. Interessei-me por esta lista e tive a ideia de olhar como as 85 obras essenciais se dividiam no tempo, numa escala secular. O quadro que resultou é muito interessante. Um traço marcante foi que, das 85 obras selecionadas, apenas 12 eram posteriores a 1600 e apenas cinco posteriores a 1700 .

\footnotetext{
${ }^{10}$ Aquelas de sacerdote, guerreiro e camponês/criador. Ver L'idéologie tripartite des Indo-Européens (Bruxelles : Latomus, 1958).

11 张岱年, 牟钟鉴 : 中国思想文化典籍导引 (中共中央党校出版社, Pékin, 1994).
} 
Obviamente, a escolha dos autores poderia ser debatida e modificada em certa medida, mas o fato permanecia. Sua significação aparece quando se sobrepõe, à curva chinesa, uma curva comparável das obras europeias que contam para nós. Durante estes mesmos séculos, a curva da Europa é ascendente, pois representa o nascimento e desenvolvimento da Idade Moderna, onde se situam Descartes, Spinoza, Locke, Hume, Montesquieu, Voltaire, Rousseau, Constant, Tocqueville, Marx, Hegel, Nietzsche e muitos outros, só para mencionar a filosofia e o pensamento político. Esquecemos facilmente que muitas das ideias com as quais convivemos não existiram sempre e que nós as devemos a estes pensadores. Durante os mesmos séculos, a vida intelectual foi, decerto, animada na China também, mas não produziu muitas ideias úteis para a atualidade. É um fato que precisa ser reconhecido e que explica também, em parte, porque o passado pesa tanto, embora de forma invisível, sobre a China de hoje.

Em poucas palavras, abordei vários problemas, simplificando-os com audácia, ou mesmo certa temeridade que meus amigos sinólogos presentes poderão talvez criticar ou desculpar. Um destes pontos foi a indispensável clarificação do sentido das palavras. Outro foi a ausência de narrativa e as causas dessa ausência. Uma terceira foi a especificidade da tradição política chinesa. Não falei do problema que há na transição, obviamente desejável, desta concepção tradicional do poder rumo a uma sociedade democrática. Em suma, há uma infinidade de coisas a dizer. Escolhi algumas, sem saber se fiz uma boa escolha, mas foi minha contribuição para hoje. 